\title{
Neonatal mouse immunity against group B streptococcal infection by maternal vaccination with recombinant anti-idiotypes
}

\author{
Walter Magliani ${ }^{1}$, Luciano Polonelli ${ }^{1}$, Stefania Conti ${ }^{1}$, Antonella Salati ${ }^{1}$, \\ Pier Francesco Rocca ${ }^{2}$, Vitaliano Cusumano ${ }^{2}$, Giuseppe Mancuso ${ }^{2} \&$ Giuseppe Teti $^{2}$ \\ 'Istituto di Microbiologia, Facoltà di Medicina e Chirurgia, \\ Università degli Studi di Parma, Via Gramsci 14, 1-43100 Parma, Italy \\ ${ }^{2}$ Istituto di Microbiologia, Facoltà di Medicina e Chirurgia, Università degli Studi di Messina, \\ Via Consolare Valeria 1, I-98125 Messina, Italy \\ Correspondence should be addressed to G.T.
}

\begin{abstract}
We investigated whether immunization with recombinant anti-idiotypic antibody fragments mimicking the conformation of the capsular antigen can protect against infection by group $B$ streptococcus, an important neonatal pathogen. Single-chain fragment-variable anti-idiotypes competed with the type III carbohydrate for binding to type-specific antibodies and elicited, in mice, the production of protective immunoglobulins reacting against the type III polysaccharide. Moreover, maternal immunization with soluble or phage-displayed fragments protected neonatal mice against streptococcal infection. These data indicate that recombinant anti-idiotypic antibodies may be useful in developing protein images of relevant carbohydrate epitopes and, ultimately, in preventing infections by encapsulated bacteria.
\end{abstract}

Group B streptococci (GBS) are recognized as a major cause of sepsis and meningitis in neonates and in patients with underlying conditions such as diabetes, cirrhosis and solid tumors. Because the incidence of mortality and permanent disabilities remains high despite appropriate therapy, the development of vaccines has attracted considerable attention. The type-specific capsular polysaccharide $(\mathrm{CHO})$ has anti-phagocytic properties and is considered the main virulence factor of GBS (refs. 1,2). In most countries, type III strains are responsible for a significant percentage of serious neonatal infections and for the large majority of meningitis cases ${ }^{1}$.

Immunization of fertile women with a combination of typeantigens has been proposed as a strategy for the prevention of neonatal disease, with the rationale that specific antibodies passing through the placental barrier can prevent neonatal infection $^{3}$. Indeed, a significant correlation has been shown between GBS infection in neonates and low levels of maternal antibodies to the type-specific CHO (refs. 3,4).

Unconjugated capsular polysaccharides are poorly effective and the incidence of non-responders is unacceptably high ${ }^{5}$. The poor immunogenicity of capsular antigens has been attributed to their carbohydrate nature with the resulting inability to stimulate T cell-dependent help ${ }^{6}$.

A widely accepted method to potentiate the immunogenicity of polysaccharide antigens is by conjugation with proteins. This approach has been successful in the prevention of Haemophilus influenzae type $\mathrm{b}$ infections ${ }^{7}$. Type III CHOs conjugated with tetanus toxoid ${ }^{8-11}$ or GBS proteins ${ }^{12,13}$ are being evaluated as potential vaccines for the prevention of GBS disease. Type III CHOtetanus toxoid conjugates produced high serum levels of type-specific antibody in healthy volunteers ${ }^{10}$ and baboons ${ }^{11}$.

An alternative strategy to obtain effective and boostable anti- body responses against carbohydrate antigens involves the development of protein molecules mimicking the conformation of relevant carbohydrate epitopes. The advantage of this approach is that, by their chemical nature, proteins have an intrinsic ability to stimulate T-cell help in an antigen-specific manner.

Peptides $^{14,15}$ as well as anti-idiotypic antibodies ${ }^{16}$ can potentially mimic carbohydrate epitopes. A monoclonal anti-idiotypic antibody coupled to a carrier protein was used as a surrogate vaccine to immunoprotect BALB/c mice against lethal Streptococcus pneumoniae infection ${ }^{17}$. Active immunoprotection in this model was referable to high titers of antibodies to phosphorylcholine. Monoclonal antibodies mimicking the K13 Escherichia coli ${ }^{18}$ or the group C Neisseria meningitidis ${ }^{19}$ capsular antigens have also been described.

Recently, antibody-variable region fragments obtained by recombinant DNA technology have attracted considerable attention, since these products can be easily engineered for specific purposes. In this report we describe the construction and vaccinal potential of single-chain fragment-variable ( $\mathrm{ScFv}$ ) anti-idiotypic antibodies. These ScFv antibodies stimulated the production of antibodies directed against the type III capsular polysaccharide of GBS which exerted passive and active protective immunity in a neonatal mouse model.

\section{Inhibition of agglutination by anti-idiotypic ScFv}

After we selected the six phage clones which reacted with MAb P9D8 in ELISA, we tested the corresponding soluble ScFv antibodies for their ability to inhibit GBS agglutination by antitype III antibodies. Preliminary results indicated that all of the selected $\mathrm{ScFv}$ were capable of preventing MAb P9D8-induced agglutination, and that the ScFv antibody we named $\mathrm{C} 10 \mathrm{ScFv}$ showed the highest potency (data not shown). Table 1 shows 


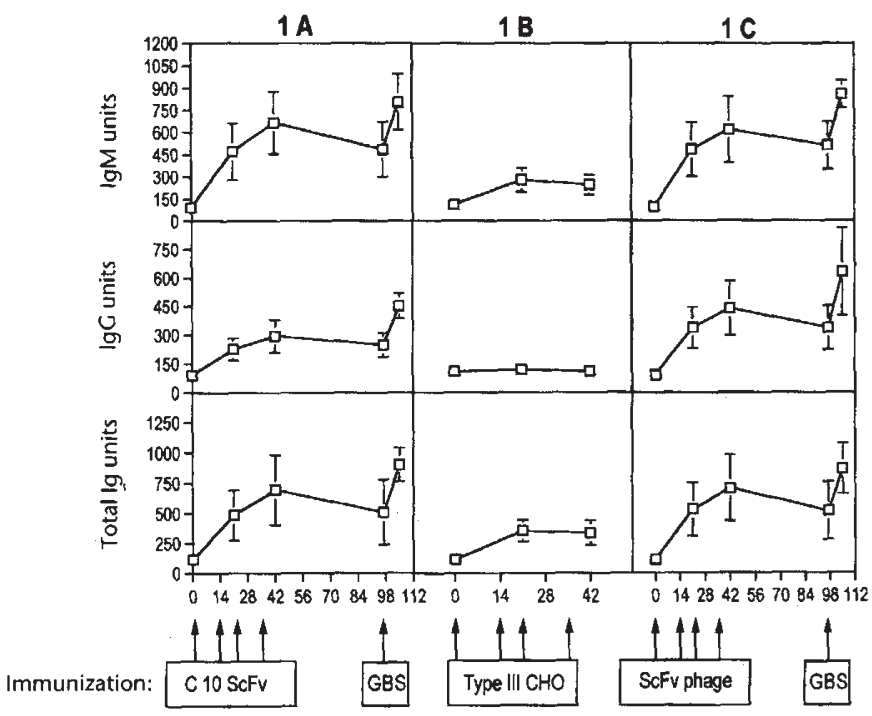

Fig. 1 Anti-type III antibody levels in sera collected at various times after immunization with $\mathrm{C} 10$ SCFV (1A), unconjugated type III CHO (1B) or phage-displayed $\mathrm{C} 10 \mathrm{ScFv}(1 \mathrm{C})$. Mice were immunized with these antigens or heat-killed CBS at the indicated times (arrows). Points and bars represent means \pm standard deviations of five determinations, each conducted on a different serum sample.

that at concentrations of $15 \mu \mathrm{g} / \mathrm{ml}$ or more $\mathrm{C} 10 \mathrm{ScFv}$ was capable of inhibiting the agglutination of GBS cells induced by MAb P9D8. Significantly, up to $240 \mu \mathrm{g} / \mathrm{ml}$ of the irrelevant $\mathrm{H} 6$ ScFv antibody, which is unable to bind MAb P9D8 (ref. 20), did not affect agglutination (Table 1 ). The specificity of this test for the type III CHO was confirmed by the ability of purified typespecific antigen, but not group-specific antigen, to inhibit the agglutination of type III GBS by MAb P9D8 (Table 1).

The ability of C10 ScFv to prevent agglutination suggested that the fragment recognized an idiotypic determinant of MAb P9D8 that was either similar or identical to the paratopic combining site. To discriminate between these two possibilities, agglutination-inhibition experiments were performed using rabbit anti-type III antibodies, in place of MAb P9D8, to induce agglutination. The rationale behind these studies is that idiotypes unrelated to antigen binding are rarely present in antibodies raised in different species ${ }^{16}$.

Table 1 shows that C10 ScFv was capable of inhibiting agglutination induced by rabbit antibodies. This indicated that $\mathrm{C} 10$ $\mathrm{ScFv}$ was specific for the antigen-binding site of anti-type III $\mathrm{CHO}$ antibodies, and could, therefore, mimic the conformation of the nominal type III antigen. In addition, because MAb P9D8 is highly specific for a sialic-acid-dependent epitope of the type III CHO (ref. 21), it was likely that the anti-idiotypic C10 ScFv mimicked this conformational epitope. This was confirmed by the observation that up to $240 \mu \mathrm{g} / \mathrm{ml}$ of C10 ScFv was unable to compete with antibodies to pneumococcal type XIV (which is identical to de-sialated type III $\mathrm{CHO}$ ) in agglutination-inhibition tests with the GBS COH1-11 mutant strain with a capsule lacking sialic acid ${ }^{22}$ (data not shown).

\section{Immunizing properties of $\mathrm{C} 10 \mathrm{ScFv}$}

Mice were immunized with $50 \mu \mathrm{g}$ of soluble $\mathrm{C} 10$ or $\mathrm{H} 6 \mathrm{ScFv}$, thereafter receiving recall injections of the same antigen at 14 , 21 and 35 days after the primary immunization. As a control,

mice were immunized with purified, unconjugated capsular polysaccharide $(50 \mu \mathrm{g})$. Serum samples were collected at the indicated times and tested for antibody levels by ELISA using the type III $\mathrm{CHO}$ as the coating antigen. Sera from mice vaccinated with $\mathrm{C} 10 \mathrm{ScFv}$ showed significant $(P<0.05)$ elevations in antitype III IgM and IgG, compared with preimmune values (Fig. 1a). Sera from mice immunized with the control H6 ScFv antibody did not show any significant anti-type III CHO response (not shown). Anti-type III $\mathrm{CHO}$ antibody elevations induced by $\mathrm{C} 10$ ScFv were boosted by repeated vaccinations and slowly declined after the last immunization with C10 ScFv at day 35 (Fig. 1a). In contrast, the type III CHO induced modest anti-type III responses that were not boosted by repeated immunizations and were IgM only (Fig. $1 b$ ).

In order to determine if ScFv antibody immunizations primed the mice for responding to the nominal antigen, C10 ScFv-immunized animals were boosted with killed type-III GBS at day 97. Killed bacteria produced a sharp rise in anti-type III CHO antibodies as evidenced by higher titers of IgM, IgG and total antibodies at day 104, relative to day 97 values (Fig. 1a). These data indicate that $\mathrm{C} 10 \mathrm{ScFv}$ could prime the mice for increased responses on exposure to the pathogen.

We also determined whether phages displaying C10 ScFv on their surface could also induce anti-type III $\mathrm{CHO}$ responses. Antitype III $\mathrm{CHO}$ antibody responses in mice immunized with phage-displayed C10 fragments (Fig. 1c) were similar to those observed with purified $\mathrm{C} 10 \mathrm{ScFv}$ using the same immunization schedule and doses (that is, $50 \mu \mathrm{g}$ of phages per mouse). In contrast, control phage-displayed $\mathrm{H} 6$ fragments were ineffective (data not shown).

\section{Neonatal protection studies}

Sera from mice immunized with $\mathrm{C} 10 \mathrm{ScF}$ were evaluated for their ability to passively protect pups against lethal infection with highly virulent GBS. Six-week-old mice were immunized at days $0,14,21$ and 35 with $50 \mu \mathrm{g}$ of purified or phage-displayed C10 ScFv and serum samples were obtained on day 42 . Twenty five $\mu$ l of diluted sera were injected subcutaneously

Table 1 Ability of anti-idiotypic ScFv antibodies to inhibit GBS agglutination by type-III-specific antibodies

Anti-type III antibody

None

MAb P9D8 ascites MAb P9D8 ascites MAb P9D8 ascites MAb P9D8 ascites MAb P9D8 ascites MAb P9D8 ascites MAb P9D8 ascites MAb P9D8 ascites MAb P9D8 ascites MAb P9D8 ascites

Absorbed rabbit serum ${ }^{b}$ Absorbed rabbit serum Absorbed rabbit serum Absorbed rabbit serum Absorbed rabbit serum Absorbed rabbit serum Absorbed rabbit serum Absorbed rabbit serum
Inhibitor

None

None

Type III CHO $(5 \mu \mathrm{g} / \mathrm{ml})$ Group CHO $(25 \mu \mathrm{g} / \mathrm{ml})$

C10 ScFv $(240 \mu \mathrm{g} / \mathrm{ml})$

C10 ScFv $(120 \mu \mathrm{g} / \mathrm{ml})$

C10 ScFv $(60 \mu \mathrm{g} / \mathrm{ml})$

C10 ScFv $(30 \mu \mathrm{g} / \mathrm{ml})$

C10 ScFv $(15 \mu \mathrm{g} / \mathrm{ml})$

C10 ScFv $(7.5 \mu \mathrm{g} / \mathrm{ml})$

H6 ScFv $(240 \mu \mathrm{g} / \mathrm{ml})$

None

Type III CHO $(5 \mu \mathrm{g} / \mathrm{ml})$

Group CHO $(25 \mu \mathrm{g} / \mathrm{ml})$

C10 ScFv $(240 \mu \mathrm{g} / \mathrm{ml})$

C10 SCFv $(120 \mu \mathrm{g} / \mathrm{ml})$

C10 ScFv $(60 \mu \mathrm{g} / \mathrm{ml})$

C10 ScFv $(30 \mu \mathrm{g} / \mathrm{ml})$

H6 ScFv $(240 \mu \mathrm{g} / \mathrm{ml})$
Agglutination

$+$

$-$

$-$

$-$

-

ased at a final dilution of 1:125,000. Used at a final dilution of 1:500. 
Table 2 Effects on lethality of sera from mice immunized with ScFv antibody in a neonatal model of GBS disease
Treatment

Preimmune serum

Anti-H6 ScFv serum

Anti-C10 ScFv serum no. 1

Anti-C10 ScFv serum no. 3

Anti-C10 ScFv serum no. 4

Anti-C10 ScFv serum no. 5

Anti-C10 phage-SCFv serum no.2

Anti-C10 phage-ScFv serum no.3
Anti-C10 ScFv serum no. 2
Anti-C10 phage-ScFv serum no. 1

Serum dilutions

\begin{tabular}{ccccc}
$1: 5$ & $1: 10$ & $1: 20$ & $1: 40$ & $1: 80$ \\
$10 / 12^{\mathrm{a}}$ & $12 / 13$ & $23 / 26$ & $20 / 22$ & \\
$4 / 5$ & $6 / 8$ & $9 / 10$ & & \\
$0 / 4^{\mathrm{b}}$ & $0 / 5^{\mathrm{b}}$ & $1 / 10^{\mathrm{b}}$ & $2 / 10^{\mathrm{b}}$ & $4 / 7$ \\
& $0 / 9^{\mathrm{b}}$ & $1 / 13^{\mathrm{b}}$ & $7 / 8$ & \\
& $0 / 9^{\mathrm{b}}$ & $6 / 8$ & $7 / 7$ & \\
& & $1 / 10^{\mathrm{b}}$ & $3 / 10^{\mathrm{b}}$ & $4 / 4$ \\
& & $2 / 12^{\mathrm{b}}$ & $7 / 10$ & \\
$0 / 10^{\mathrm{b}}$ & & $10 / 10$ & & \\
& $2 / 8^{\mathrm{b}}$ & $0 / 5^{\mathrm{b}}$ & $0 / 4^{\mathrm{b}}$ & $4 / 5$ \\
& & $2 / 10^{\mathrm{b}}$ & $1 / 11^{\mathrm{b}}$ & $8 / 10$ \\
\hline
\end{tabular}

a Dead/total no. at 5 days after challenge. Shown are cumulative results from 5 experiments. Neonatal mice were injected s.c. with $20 \mu \mathrm{l}$ of serum dilutions and infected with $100 \mathrm{CFU}$ of GBS. ${ }^{b}$ Significantly different from normal serum by Fisher exact test. form of immunological memory. Also, the former response was both IgG and IgM, while the latter was IgM only. Accordingly, in our study, maternal immunization with $\mathrm{C} 10 \mathrm{ScFv}$ protected neonatal mice against lethal GBS infection, likely by inducing the production of transplacentally acquired IgG.

ScFv antibody or ScFv-based molecules might be used to prevent GBS disease. However, our study was not designed to compare the immunogenic properties of anti-idiotypic ScFv antibodies with those of glycoconjugates, which are producing promising results in healthy volunteers ${ }^{10}$. Our data is relevant not only to GBS infections but also to the more general problem of inducing effective immune responses against carbohydrate antigens. Conjugation with protein carriers is a widely accepted method to in-

(s.c.) in neonatal mice less than $24 \mathrm{~h}$ old at $6 \mathrm{~h}$ before challenge with a $90 \%$ lethal dose of GBS. Sera from mice immunized with either soluble or phage-displayed C10 ScFv were capable of conferring significant passive immunoprotection against GBS challenge, compared with preimmune sera (Table 2 ). The protective titers of sera from $\mathrm{C} 10 \mathrm{ScFv}$-immunized mice ranged from $1: 10$ to $1: 40$ (Table 2 ). In contrast, sera from animals immunized with the irrelevant H6 ScFv antibody were non-protective (Table 2).

To determine whether maternal immunization with recombinant anti-idiotypic fragments was effective in protecting neonatal mice against infection, four week-old female mice were immunized three times with $50 \mu \mathrm{g}$ of soluble or phagedisplayed $\mathrm{ScFv}$ antibody, mated and boosted again at 35 days after the initial immunization. Neonatal pups were then infected with a $90 \%$-lethal dose of GBS. Neonates born to mothers immunized with soluble or phage-displayed C10 ScFv were significantly protected against GBS-induced lethality, relative to those born to mothers immunized with the irrelevant $\mathrm{H} 6$ ScFv antibody (Table 3).

\section{Discussion}

Our study describes an anti-idiotypic ScFv antibody capable of mimicking the antigenic properties of the type III capsular polysaccharide of GBS. This ScFv antibody competed with the carbohydrate antigen for binding to type III-specific antibodies raised in two different species and induced the production of protective anti-type III antibodies in mice.

The immune response induced by the anti-idiotypic ScFv antibody differed from that induced by the nominal carbohydrate antigen. The response induced by the ScFv antibody was boostable, while the type III CHO was unable to produce any

Table 3 GBS-induced lethality in neonatal mice born to mothers immunized with anti-idiotypic ScFv antibody

$\begin{array}{lc}\text { Immunizing antigen } & \begin{array}{r}\text { Neonatal lethality } \\ \text { dead/total (\%) }\end{array} \\ \text { H6 ScFv (control) } & 19 / 21(90) \\ \text { C10 ScFv } & 8 / 35(23)^{a} \\ \text { phage-H6 ScFv (control) } & 19 / 22(86) \\ \text { phage-C10 ScFv } & 5 / 31(16)^{a}\end{array}$

aSignificantly different from control by Fisher exact test. crease the immunogenicity of carbohydrate antigens, even if problems still exist, including (in some cases), persistant low antigenicity of the sugar moiety and cross-reactivity with human tissues ${ }^{7,23,24}$. Thus, it may be worthwhile to investigate alternative strategies, such as the production of protein mimics of carbohydrate epitopes. The feasibility of this approach has been shown in studies using anti-idiotypic monoclonal antibodies mimicking the capsular polysaccharides of three bacterial pathogens ${ }^{17-19}$, as well as using peptides mimicking a protective carbohydrate epitope of the HIV gp 160 (ref. 15).

We have shown that $29 \mathrm{kDa} \mathrm{ScFv}$ antibodies can be effectively employed in place of whole antibodies, as anti-idiotypic immunogens. Although these fragments are monovalent, they tend to form higher molecular mass dimers and multimers ${ }^{25}$, which may increase their immunogenicity. These molecules have some potential advantages as surrogate immunogens. $\mathrm{ScFv}$ antibodies can be easily tailored for specific purposes ${ }^{26}$. For example, additional immunogenic sequences could be incorporated, or single aminoacids inserted, to facilitate subsequent derivatization with carrier proteins. Moreover, the genes coding for $\mathrm{ScFv}$ antibodies could be used for direct insertion into live vectors or in modern approaches of DNA immunization. Here we have shown that the anti-idiotypic strategy can be used experimentally to prevent lethal GBS infection. Anti-idiotypic ScFv antibodies may be useful to develop protein internal images of relevant carbohydrate epitopes and, ultimately, in preventing infections caused by encapsulated bacteria.

\section{Methods}

Bacterial strains and reagents. Strain $\mathrm{H} 738$ (type III), was provided by B. Anthony (National Institutes of Health, Bethesda, Maryland). Strain $\mathrm{COH} 1$ (also GBS type III) and the isogenic mutants $\mathrm{COH} 1-13$ (unencapsulated) and $\mathrm{COH} 1-11$ (with a capsule lacking sialic acid) were a gift from C. Rubens (University of Washington, Seattle, Washington) ${ }^{2,22}$. Type III and group-specific CHOs were purified by ion-exchange chromatography and gel filtration from the culture supernatant of strain $\mathrm{H} 738$, as described ${ }^{27,28}$. The type III CHO contained $24 \%$ sialic acid by weight ${ }^{29}$. This preparation was considered of sufficient purity because it contained, on a weight basis, $<0.5 \%$ proteins (BioRad protein assay, BioRad Laboratories), nucleic acids (absorbance at $250 \mathrm{~nm}$ ) or rhamnose $\mathrm{s}^{30}$, a major constituent of the group antigen.

The properties and purification of the murine monoclonal antibody MAb P9D8 have been described ${ }^{21}$. This monoclonal antibody binds to a sialic acid-dependent epitope of the type III $\mathrm{CHO}$, promotes opsonophagocytic killing of GBS and has significant protective activities 
against GBS-induced lethality when passively administered to neonatal rats or mice.

Rabbit anti-type III GBS and anti-type XIV pneumococcus sera (Statens Serum Institute, Copenhagen, Denmark) were absorbed with heat-killed $\left(80^{\circ} \mathrm{C}\right.$ for $45 \mathrm{~min}$ ) unencapsulated $\mathrm{GBS}$ (strain $\mathrm{COH} 1-13$ ) to remove nontype specific anti-GBS antibodies. After absorbtion, these preparations reacted with type III GBS, but not with unencapsulated strains or strains belonging to other serotypes.

Production of anti-idiotypic ScFv antibodies. Phage libraries were produced as described ${ }^{20}$. Briefly, male BALB/C mice ( 8 weeks old) were injected s.c. on days 0 and 15 with $50 \mu \mathrm{g}$ of MAb P9D8 in $0.2 \mathrm{ml}$ of complete Freund's adjuvant (Difco) and on days 21 and 28 with the same dose of antigen in $0.2 \mathrm{ml}$ of incomplete Freund's adjuvant (Difco). A final booster injection ( $50 \mu \mathrm{g}$ of antigen in saline) was given intraperitoneally on day 35 , and three days later the mice were killed and their spleens removed. Spleen cells were resuspended in tissue culture medium and dispensed into $75 \mathrm{~cm}^{2}$ tissue culture flasks previously coated with MAb P9D8 $(25 \mu \mathrm{g} / \mathrm{ml})$ in carbonate buffer $(\mathrm{pH} 9.6)$ and blocked with $2 \%$ non-fat dry milk (Sigma).

After extracting and reverse-transcribing the mRNA from adherent cells, the genes encoding variable heavy and light chains were cloned in recombinant phages displaying ScFv antibodies on their tips using a commercial system (Recombinant Phage Antibody System, Pharmacia) ${ }^{20}$.

Phage selection was done by two rounds of panning on tissue culture flasks coated with $5 \mathrm{ml}$ of MAb P9D8 $(10 \mu \mathrm{g} / \mathrm{ml})$ in carbonate buffer $(\mathrm{pH}$ 9.6), as described ${ }^{20}$ Recombinant phage supernatants were then screened in the wells of microtiter plates previously coated with MAb P9D8 $(10 \mu \mathrm{g} / \mathrm{ml})$. Recombinant phages giving a positive ELISA signal were then used to infect $E$. coli HB2151 to produce soluble ScFv antibodies ${ }^{20}$. Western blot analysis of affinity-purified ScFv antibodies ${ }^{20}$ showed that they all consisted of single monomers with the approximate molecular weight of $29 \mathrm{kDa}$.

GBS agglutination inhibition assay. In preliminary studies, a bacterial agglutination assay was set up by mixing killed GBS with type III-specific antibodies in U-bottom wells of microtiter plates. This test correlated strongly with a previously described ELISA inhibition assay ${ }^{21,31}$ and produced the same results for the relative potencies of various inhibitors in competing with the type $\mathrm{CHO}$ for binding to specific antibodies. In the agglutination inhibition test, type III GBS, but not unencapsulated mutants, were agglutinated by either MAb P9D8 or absorbed rabbit serum. For the agglutination inhibition assay, inhibitors $(50 \mu \mathrm{l}$ in PBS supplemented with $1 \%$ bovine serum albumin) were mixed with an equal volume of antibody-containing solutions in the wells of microtiter plates. Antibody solutions were adjusted to achieve final dilutions corresponding to two times the minimal concentration needed to induce agglutination in the absence of inhibitors. After incubating the inhibitors with type-specific antibody or absorbed rabbit serum for $30 \mathrm{~min}$ at $37^{\circ} \mathrm{C}, 50 \mu \mathrm{l}$ of the killed-GBS suspension was added. This suspension was obtained after killing GBS strain $\mathrm{H} 738$ (type III) in $3 \%$ formalin ( 3 days at $4{ }^{\circ} \mathrm{C}$ ), and resuspending the washed pellet in PBS-albumin to a concentration of $5 \times 10^{8} \mathrm{cells} / \mathrm{ml}$. The plates were incubated for $4 \mathrm{~h}$ at $37^{\circ} \mathrm{C}$ and then overnight at room temperature. Results were assessed visually.

Animal immunization. Male BALB/C mice ( 6 weeks old) were immunized with either purified $\mathrm{ScFv}$ antibody, polyethylene glycol- $\mathrm{NaCl}$ precipitated phage-displayed $\mathrm{SCFv}^{20}$ or purified, unconjugated type III CHO. A first s.C. injection of $50 \mu \mathrm{g}$ of antigen in $0.2 \mathrm{ml}$ of complete Freund's adjuvant was followed, after 2 weeks, by a second s.c. administration of the same dose in $0.2 \mathrm{ml}$ of incomplete Freund's adjuvant. Two additional injections of 50 $\mu \mathrm{g}$ of immunogen in $0.2 \mathrm{ml}$ of saline were given intraperitoneally at 21 and 35 days after the initial immunization.

Sera were taken from the retroorbital plexus at the indicated times after immunization and analyzed for antibodies directed against the type III antigen using an ELISA in which microtiter plates were coated with $1 \mu \mathrm{g} /$ well of tyrosylated type III CHO (ref. 21). Bound antibodies were detected with biotinylated polyvalent anti-mouse IgC (Vector Laboratories) or with $\mu$ - or $\gamma$ chain-specific alkaline phosphatase horse anti-mouse Ig (Sigma), as described ${ }^{27}$. A positive control consisting of pooled sera from mice immunized with killed type III CBS was included in each determination. Results were expressed in arbitrary units equal to the ratio between absorbance of test serum and absorbance of the positive control serum multiplied by 1,000 .

Neonatal model of GBS disease. To study the protective effects of passively administered sera, a neonatal mouse model of GBS infection was used $^{32-34}$. The same model was also employed to assess the efficacy of active maternal immunization in protecting neonates from infection. To assess the protective activity of sera, neonatal ( $24 \mathrm{~h}$ old) Balb/c mice were randomly assigned to control or experimental groups, marked and kept with their mothers. Pups were inoculated s.c. with $25 \mu \mathrm{l}$ of the indicated dilutions of normal or immune sera. Six hours later, the animals were challenged s.c. with the $\mathrm{COH} 1$ strain (100 CFU in $25 \mu \mathrm{l}$ in PBS). Mortality was assessed every $12 \mathrm{~h}$ for $5 \mathrm{~d}$. Deaths rarely occurred after this time.

To assess the effects of maternal immunization, 4-week-old female mice were immunized with soluble or phage displayed SCFv antibody. A first s.c. injection of $50 \mu \mathrm{g}$ of antigen in $0.2 \mathrm{ml}$ of complete Freund's adjuvant was followed after 2 weeks by a second s.c. administration of the same dose in $0.2 \mathrm{ml}$ of incomplete Freund's adjuvant. One additional injection of $50 \mu \mathrm{g}$ of immunogen in $0.2 \mathrm{ml}$ of saline was given s.c. at 21 days after the initial immunization. Females were then mated at 31 days and boosted at 35 days with $50 \mu \mathrm{g}$ of antigen in saline administered s.c. Neonatal mice born to ScFv-immunized mothers were challenged with GBS as detailed above.

Statistical analysis. Differences between antibody concentrations in mouse sera were analyzed for statistical significance using one way analysis of variance and the Student-Keuls-Newman test. Differences in lethality were analyzed with Fisher exact test.

\section{RECEIVED 4 FEBRUARY; ACCEPTED 20 APRIL 1998}

1. Baker, C.J. \& Edwards, M.S. In Infectious Diseases of the Fetus and Newborn Infant (eds. Remington, J. \& Klein, J.O.) 980-1054 (W.B. Saunders,-Philadelphia, PA 1995).

2. Rubens, C.E., Wessels, M.R., Heggen, L.M. \& Kasper, D.L. Transposon mutagenesis of group B streptococcal type III capsular polysaccharide: correlation of capsule expression with virulence. Proc. Natl. Acad. Sci. USA 84, 7208-7212 (1987)

3. Baker, C.J., Edwards, M.S. \& Kasper, D.L. Role of antibody to native type III polysaccharide of group B streptococcus in infant infection. Pediatrics 68, 544-549 (1981)

4. Baker, C.J. \& Kasper, D.L. Correlation of maternal antibody deficiency with susceptibility to neonatal group B streptococcal infection. N. Engl. J. Med. 294, 753-756 (1976).

5. Baker, C.J. et al. Immunization of pregnant women with a polysaccharide vaccine of group B Streptococcus. N. Engl. I. Med. 319, 1180-1185 (1988).

6. McLeod Griffiss, I., Apicella, M.A., Greenwood B. \& Makela P.H. Vaccines against encapsulated bacteria: a global agenda. Rev. Infect. Dis. 9, 176-181 (1987).

7. Molecular and Clinical Aspects of Bacterial Vaccine Development (eds. Ala'Aldeen, D.A.A. \& Hormaeche, C.E.) (John Wiley \& Sons, Chichester, UK, 1995).

8. Lagergärd, T., Shiloach, J., Robbins, J.B. \& Schneerson, R. Synthesis and immunological properties of conjugates composed of group B streptococcus type III capsular polysaccharide covalently bound to tetanus toxoid. infect. Immun. 58, 687-694 (1990).

9. Paoletti, L.C. et al. Neonatal mouse protection against infection with multiple group B streptococcal (GBS) serotypes by maternal immunization with a tetravalent GBS polysaccharide-tetanus toxoid conjugate vaccine. Infect. Immun. 62, 3236-3243 (1994).

10. Kasper, D.L. et al. Immune response to type III streptococcal polysaccharide-tetanus toxoid conjugate vaccine. I. Clin. Invest. 98, 2308-2314 (1996).

11. Paoletti, L.C., Kennedy, R.C., Chanh, T.C. \& Kasper, D.L. Immunogenicity of group B Streptococcus type III polysaccharide-tetanus toxoid vaccine in baboons. Infect. Immun. 64, 677-679 (1996).

12. Madoff, L.C., Michel, J.L., Gong, E.W., Rodewald, A.K. \& Kasper,D.L. Protection of neonatal mice from group $B$ streptococcal infection by maternal immunization with beta c protein. Infect. Immun. 60, 4989-4994 (1992).

13. Larsonn, C., Stålhammar-Carlemalm, M., \& Lindahl, G. Experimental vaccination against group B streptococcus, an encapsulated bacterium, with higly purified preparations of cell surface proteins rib and a. infect. Immun. 64, 3518-3523 (1996).

14. Westerink, M.A.J., Giardina, P.C., Apicella, M.A., \& Kieber-Emmons, T. Peptide mimicry of the meningococcal group $C$ capsular polysaccharide. Proc. Natl. Acad. SCi. USA 92, 4021-4025 (1995).

15. Agadjanyan, M. et al. Peptide mimicry of carbohydrate epitopes on human immunodeficiency virus. Nature Biotechnol. 15, 547-551 (1997) 
16. Westerink, M.A., Muller, E. \& Apicella, M.A. In Idiotypic network and disease (eds. Cerney, J. \& Hiernaux, J.) 107-119 (American Society for Microbiology, Washington, DC 1990)

17. McNamara, M., Ward, R.E. \& Kohler, I.J. Monoclonal idiotype vaccine against Streptococcus pneumoniae infection. Science 226, 1325-1326 (1984).

18. Stein, K.E. \& Soderstrom, T. Neonatal administration of idiotype or anti-idiotype primes for protection against $E$. coli $\mathrm{K} 13$ infection in mice. /. Exp. Med. 160 1001-1041 (1984).

19. Westerink, M.A., Campagnari, A.A., Wirth, M.A., \& Apicella, M.A. Development and characterization of an anti-idiotype antibody to the capsular polysaccharide of Neisseria meningitidis serogroup C. Infect. immun. 56, 1120-1127 (1988).

20. Magliani, W. et al. Therapeutic potential of anti-idiotypic single chain antibodies with yeast killer toxin activity. Nature Biotechnol. 15, 155-158 (1997).

21. Teti, G. et al. Specificity and protective activity of murine monoclonal antibodies directed against the capsular polysaccharide of type III group B streptococci. Hybridoma 11, 13-22 (1992).

22. Wesseis, M.R., Haft, R.F., Heggen, L.M. \& Rubens, C.E. Identification of a genetic locus essential for capsule sialation in type III group B streptococci. Infect. Immun. $60,392-400(1992)$.

23. Finne, I., Leinonen, M. \& Makela, P.H. Antigenic similarities between brain components and bacteria causing meningitis. Implications for vaccine development and pathogenesis. Lancet 11, 355-357 (1983).

24. Frasch, C.E. Vaccines for prevention of meningococcal disease. Clin. Microbiol. Rev 2, \$134-5138 (1989)

25. Kortt, A.A. et ol. Recombinant antineuraminidase single chain Fv antibody: charac- terization, formation of dimer and higher molecular mass multimers and the solution of the crystal structure of the SCFv-neuraminidase complex. Eur.j. Immunol. 23, 206-211 (1994).

26. Gherardi, E. \& Milstein, C. Original and artificial antibodies. Nature 357, 201-202 (1992).

27. Teti, G., Tomasello, F. \& Mancuso, G. Synthesis and immunological properties of an O-stearoyl polysaccharide from group B streptococci. /. Immunol. Res. 4, 67-72 (1992).

28. Mancuso, G., Tomasello, F., von Hünolstein, C., Orefici, G. \& Teti, G. Induction of tumor necrosis factor alpha by the group- and type-specific polysaccharides from type III group B streptococci. Infect. Immun. 62, 2748-2753 (1994).

29. Aminoff, D. Methods for the quantitative estimation of $\mathrm{N}$-acetylneuramic acid and their applications to hydrolisates of sialomucoids. Biochem. 1. 81, 384-390 (1961).

30. Dische, Z., \& Shettles, R.B. A specific color reaction of methylpentoses and a spectrophotometric micromethod for their determination. J. Biol. Chem. 17, 595-599 (1948).

31. Teti, G., Mancuso, G. \& Tomasello F. Cytokine appearance and effects of antitumor necrosis factor antibodies in a neonatal rat model of group-B streptococcal infection. Infect. Immun. 61, 227-235 (1993).

32. Mancuso, G. et al. Beneficial effects of interleukin 6 in neonatal mouse models of group B streptococcal disease. Infect. Immun. 62, 4997-5002 (1994).

33. Cusumano, $V$. et at. Role of gamma interferon in a neonatal mouse model of group B streptococcal disease. Infect. Immun. 64, 2941-2944 (1996).

34. Mancuso, $G$. et al. Role of interleukin 12 in experimental neonatal sepsis caused by group B streptococci. Infect. Immun. 65, 3731-3735 (1997). 